\title{
Understanding students' poor performance on mathematical problem solving in physics
}

\author{
Jonathan Tuminaro and Edward F. Redish \\ University of Maryland, College Park, MD 20742, tuminarj@physics.umd.edu
}

\begin{abstract}
Many introductory, algebra-based physics students perform poorly on mathematical problem solving tasks in physics. There are at least two possible, distinct reasons for this poor performance: (1) Students lack the mathematical skills needed to solve problems in physics, or (2) students do not know how to apply the mathematical skills they have to particular problem situations in physics. Many physics faculty assume that the lack of mathematical skills is the problem. We present evidence suggesting that the major source of students' errors is their failure to apply the mathematical knowledge they have or to interpret that knowledge in a physical context. Additionally, we present an instructional strategy that can help students employ the mathematical knowledge they already possess.
\end{abstract}

\begin{abstract}
Motivation
A complete understanding of the concepts in physics requires fluency in the mathematical language in which these concepts are couched. However, many introductory, algebra-based physics students perform poorly on mathematical problem solving tasks in physics. There are at least two possible, distinct reasons for this poor performance: (1) Students simply lack the mathematical skills needed to solve problems in physics, or (2) students do not know how to apply the mathematical skills they have to particular problem situations in physics.

Students' poor performance on mathematical problem solving tasks in physics has led many physics departments and instructors to adopt conceptual physics courses, which dilute mathematical problem solving or simply remove it from the curriculum. If students simply do not possess the requisite mathematical knowledge these conceptual physics courses provide them with exposure to many important physics concepts to which they would otherwise not have access. However, if students have the relevant mathematical resources, the dilution or removal of mathematical problem solving tasks in physics does not help them learn to apply these mathematical resources appropriately; instead, it robs them of the opportunity to do so.
\end{abstract}

We present case study evidence suggesting that students have the relevant mathematical knowledge, but fail to apply or interpret this knowledge in the context of physics. In addition, we present an instructional strategy that can help students employ the mathematical knowledge they already possess.

\section{Data}

The data for this study comes from about 60 hours of video-taped sessions of groups of students solving homework problems. These sessions took place in the course center, where a teaching assistant or an instructor was present to assist the students, but would not explicitly solve the homework problems for them (in contrast to what is common in many recitation sessions).

The student for this case study was chosen from an introductory, algebra-based physics course at the University of Maryland, College Park. The students enrolled in this course are approximately $60 \%$ female; more than $95 \%$ of the students have completed two semesters of calculus, about $50 \%$ are biological science majors, about $40 \%$ are premeds, and $70 \%$ are juniors and seniors.

The subject for this particular case study was chosen for explanation purposes only. However, the particular episode is representative of normal interactions within the course center. 


\section{The Episode}

The episode under investigation involves a single female student (pseudonym Mary) interacting with a teaching assistant during the first week of classes. The particular problem that Mary is working on states:

You are driving on the New Jersey Turnpike at $65 \mathrm{mi} / \mathrm{hr}$. You pass a sign that says "Lane ends 500 feet." How much time do you have in order to change lanes?

Mary has difficulty, so she calls the TA over to explain her problem:

...alright if I convert $65 \mathrm{mph}$ to feet per second, which is the other thing that's given in feet... So then I got 95 feet per second is what you're moving, so in 500 feet like how long? So, I was trying to do a proportion, but that doesn't work. I was like 95 feet per second...oh wait...yeah in 500 feet, like, $\mathrm{x}$ would be like the time...that doesn't_-I get like this huge number and that doesn't make any sense.

Mary correctly identifies that using a proportion could help her solve this problem, but has trouble implementing this strategy.

A common interpretation is that Mary simply lacks the mathematical sophistication to solve this problem. That is, she doesn't know how to set up the proportion correctly, or, worse, she doesn't know how to perform division reliably! If either of these interpretations were correct, a legitimate pedagogical approach would be to inculcate her on proportion and/or division problems.

However, there is an alternative interpretation. It may be that Mary has the relevant mathematical resources, but has difficulty solving this problem because:

1. she doesn't know how to use these resources to arrive at an answer,

2. her strategy for solving this problem precludes her from activating these resources, or

3. the resources that are activated preclude her from using certain strategies.

If this alternative interpretation is correct then Mary doesn't need inculcation on proportion problems, and, worse, that might not help! Rather, she needs to reframe this problem to help her activate and effectively utilize the relevant mathematical resources she already possesses. Informally, reframing is changing the way a particular situation or problem is viewed. A more formal description of reframing requires some theoretical background.

\section{Theoretical Background}

We have been working on a theoretical framework to understand how students understand mathematics in physics [1]. This framework involves many pieces, but for this study we only need three of them:

1. intuitive mathematics knowledge,

2. formal mathematics knowledge, and

3. epistemic games.

As the name indicates, intuitive mathematics knowledge is that knowledge of mathematics that is either innate or learned at a very early age; two examples are counting and subitizing. Subitizing is the ability that humans have to immediately differentiate sets of one, two, and three objects from each other [2].

Formal mathematics knowledge is learned during formal mathematics education; examples would be knowledge of multiplication tables, proportions, the Mean-Value Theorem, etc.

Epistemic games are general purpose strategies used to achieve a particular target structure. An example of an epistemic game is List Making, which involves filling out a particular target structure, namely the list. There are legitimate moves and rules that are followed during any epistemic game. In list making, legitimate moves are: adding a new item, combining two or more items into one, changing an item, splitting an item into two or more items, or deleting an item. (For an introduction to epistemic games see Collins and Ferguson [3], and for practical applications of epistemic games in the classroom see Sherry and Trigg [4].)

\section{Epistemic Games Played}

In our stated research goal we set out to present evidence that students perform poorly on mathematical problem solving tasks in physics because of their failure to apply the mathematical 
knowledge and skills that they already possess. Restating this goal in terms of the theoretical framework introduced above, we now present evidence that the epistemic game the student tacitly plays determines her success or failure in the problem solving task.

\section{Epistemic Game: Pattern Matching}

With the theoretical machinery that we've built up let us revisit Mary's initial approach to solving this problem:

So, I was trying to do a proportion, but that doesn't work. I was like 95 feet per second...oh wait...yeah in 500 feet, like, $\mathrm{x}$ would be like the time...that doesn't_-I get like this huge number and that doesn't make any sense.

The resource that is activated to solve this problem is the formal mathematics knowledge of proportions. This resource has a particular syntax associated with it: $\frac{\square}{\square}=\frac{\square}{\square}$. (The boxes are place holders indicating that any mathematical expression can be inserted.) The syntax associated with this resource cues the epistemic game of Pattern Matching. That is, Mary is attempting to fill in the syntactic structure associated with proportions with the quantities that are given in this problem. The evidence that Mary is Pattern Matching comes from her statement "like, $\mathrm{x}$, would be like the time." This example illustrates that the resource that is activated affects which epistemic game is employed.

Now that we have a technical understanding of Mary's approach to this problem in terms of the resources that are activated and the epistemic game she is playing, we can discuss reframing her approach to help her utilize some of the other resources she has and epistemic games she already knows how to play.

\section{Epistemic Game: Touchstone Example}

Earlier we informally described reframing as changing the way a particular situation is viewed. In terms of the theoretical framework introduced above, framing is a process of activations and suppressions of resources and/or epistemic games which are employed to solve a problem.
Therefore, reframing is a shift (either continuous or discrete) in the resources and/or epistemic games that are active during the problem solving process. (For more on framing and reframing see [1] or [5]).

In the case study under investigation, here's how the teaching assistant attempts to reframe Mary's initial approach:

So what if I said something like...if you're traveling 8 feet per second and you go 16 feet, how long would that take you?

The TA's reframing of this problem is an invitation to play a new epistemic game. By replacing 95 feet per second and 500 feet with 8 feet per second and 16 feet, respectively, the TA is asking Mary to play the epistemic game which we call Touchstone Example. Participants in this game use a familiar or easily understandable example to make sense of a more complex or confusing situation.

Playing the Touchstone Example epistemic game, Mary immediately responds " 2 seconds." Her immediate response is an indication that the knowledge she uses to arrive at this answer is readily available to her, suggesting she is using intuitive mathematics knowledge. In particular, she could be counting or subitizing. That is, she could be counting up the number of seconds needed to make up 16 feet. Alternatively, she could be visualizing the number of ' 8 feet per second' blocks in ' 16 feet', then using her subitizing ability she arrives at the answer of 2 seconds.

The evidence in this case does not distinguish between these interpretations; however, the evidence does indicate that the introduction of a new epistemic game cues Mary to use a new set of resources. In Mary's initial approach she is attempting to use formal mathematics knowledge of proportions within the context of the pattern matching epistemic game. By playing the Touchstone Example epistemic game Mary shifts from using formal mathematics knowledge to using intuitive mathematics knowledge. So, we see that the epistemic game being played affects which resources get activated. 
Epistemic Game: Mapping to Mathematics

Mary is able to play the Touchstone Example epistemic game, which cues her to use intuitive mathematics knowledge, but that doesn't help her with the original problem, which involves the quantities ' 95 feet per second' and ' 500 feet'. To this end the TA suggests yet another epistemic game by asking Mary:

So, how did you do that? Can you generalize that?

The TA is asking Mary to identify and articulate the formal mathematical relationship between the quantities ' 8 feet per second', ' 16 feet', and ' 2 seconds', which she found by using intuitive mathematics knowledge. This new epistemic game we call Mapping to Mathematics.

Mary responds:

Well, like, OK. Divide--the total by like how fast you're moving. Or, like how far you went by your speed will give you the time.

In this game Mary 'derives' the formal relationship between these quantities from her conceptual knowledge of these quantities, rather than using procedural knowledge of proportions to 'match' the quantities in this problem to the syntax of a proportion (her initial approach).

\section{Discussion}

There are three points that we have attempted to make. First, students have productive mathematical resources, which can be employed to solve mathematical problems in physics. The major challenge for these students is learning how to employ the mathematical resources they already possess in a physics context. Second, in attempts to help students employ the mathematical resources they already possess, we find that the epistemic games being played affect the resources that are activated and vice versa. The rigid syntactical rules associated with formal

mathematics (like $\frac{\square}{\square}=\frac{\square}{\square}$ associated with proportions) may cause students to be locked into a particular epistemic game (like Pattern Matching), which can hinder their creativity during the problem solving process. Third, reframing, an effective instructional strategy, can activate different resources and/or epistemic games, which may help students during problem solving.

\section{References}

[1] Tuminaro, J. (in preparation). A Framework for Describing Common Mathematical Errors Students Make in Introductory Physics. Unpublished doctoral dissertation, University of Maryland, College Park.

[2] Fuson, K.C. (1992). "Research on whole number addition and subtraction." In D.A. Grouws (Ed.) Handbook of Research on Mathematics Teaching and Learning; pp 247248: New York, NY: Macmillan.

[3] Collins, A. \& Ferguson, W. (1993). "Epistemic forms and epistemic games: Structures and strategies to guide inquiry." Educational Psychologist, 28(1), 25-42.

[4] Sherry, L. \& Trigg, M. (1996). "Epistemic forms and epistemic games." Educational Technology, 36(3), 38-44.

[5] Tannen, D. (1993). "What's in a Frame? Surface Evidence for Underlying Expectations." In D. Tannen (Ed.) Framing in Discourse; pp. 14-56: New York, NY: Oxford University Press. 